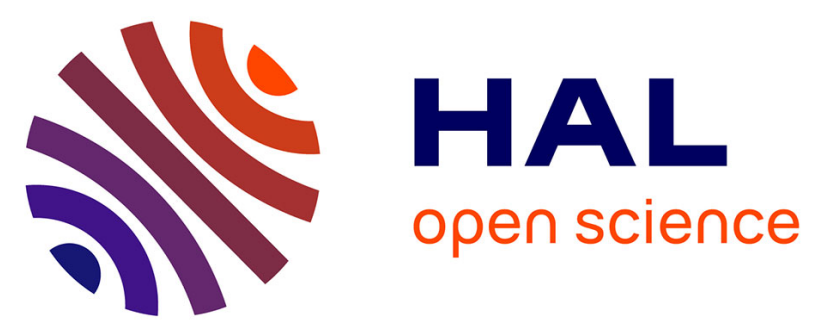

\title{
Evolution of dislocation density, size of subgrains and MX-type precipitates in a P91 steel during creep and during thermal ageing at $600{ }^{\circ} \mathrm{C}$ for more than $100,000 \mathrm{~h}$
}

Clara Panait, Anna Zielinska-Lipiec, Tomasz Koziel, Aleksandra

Czyrska-Filemonowicz, Anne-Françoise Gourgues-Lorenzon, Walter Bendick

\section{To cite this version:}

Clara Panait, Anna Zielinska-Lipiec, Tomasz Koziel, Aleksandra Czyrska-Filemonowicz, AnneFrançoise Gourgues-Lorenzon, et al.. Evolution of dislocation density, size of subgrains and MX-type precipitates in a P91 steel during creep and during thermal ageing at $600{ }^{\circ} \mathrm{C}$ for more than 100,000 h. Materials Science and Engineering: A, 2010, 527, pp.4062-4069. 10.1016/j.msea.2010.03.010 . hal-00491033

\section{HAL Id: hal-00491033}

https://hal-mines-paristech.archives-ouvertes.fr/hal-00491033

Submitted on 10 Jun 2010

HAL is a multi-disciplinary open access archive for the deposit and dissemination of scientific research documents, whether they are published or not. The documents may come from teaching and research institutions in France or abroad, or from public or private research centers.
L'archive ouverte pluridisciplinaire HAL, est destinée au dépôt et à la diffusion de documents scientifiques de niveau recherche, publiés ou non, émanant des établissements d'enseignement et de recherche français ou étrangers, des laboratoires publics ou privés. 


\title{
Evolution of dislocation density, size of subgrains and MX-type precipitates in a P91 steel during creep and during thermal ageing at $600^{\circ} \mathrm{C}$ for more than $100,000 \mathrm{~h}$
}

\author{
Clara Gabriela Panait*b,c,1, Anna Zielińska-Lipiec ${ }^{\mathrm{a}}$, Tomasz Koziel ${ }^{\mathrm{a}}$, Aleksandra Czyrska-Filemonowicz ${ }^{\mathrm{a}}$, \\ Anne-Françoise Gourgues-Lorenzon ${ }^{\mathrm{b}}$, Walter Bendick ${ }^{\mathrm{d}}$ \\ ${ }^{a}$ AGH University of Science and Technology, Al. Mickiewicza 30, 30-059, Krakow, Poland \\ ${ }^{b}$ MINES ParisTech, Centre des Matériaux, CNRS UMR 7633, BP 8791003 Evry Cedex, France \\ ${ }^{c} V$ \& $M$ France CEV, Route de Leval, B.P. 20149, 59620 Aulnoye-Aymeries, France \\ ${ }^{d}$ Salzgitter Mannesmann Forschung GmbH, Ehinger Straße 200, D-47259 Duisburg, Germany
}

\begin{abstract}
There are rather few quantitative data on the microstructure of the $9-12 \% \mathrm{Cr}$ heat resistant steels after long-term creep. This paper presents results of the quantitative measurement of the size of MX precipitates, subgrain size and dislocation density in a P91 steel that had been creep tested for $113,431 \mathrm{~h}$ at $600^{\circ} \mathrm{C}$. The same measurements were conducted in the same P91 steel in the as received conditions.

Transmission electron microscopy investigations were conducted using thin foils and revealed a decrease in dislocation density and an increase in subgrain size after creep exposure. MX carbonitrides are very stable during thermal and creep exposure of $\mathrm{P} 91$ steel at $600^{\circ} \mathrm{C}$ up to $113,431 \mathrm{~h}$.

Electron Backscatter Diffraction (EBSD) investigations also revealed a significant change in the substructure of the steel after creep exposure.
\end{abstract}

Key words: dislocation density, MX-type precipitates, P91 steel, subgrains, creep

\section{Introduction}

9-12\% chromium heat resistant steels are used for high temperature applications, in particular in fossil and nuclear power plants. In service, under high temperature $\left(500^{\circ} \mathrm{C}-600^{\circ} \mathrm{C}\right)$ there is a microstructural evolution of these steels such as precipitation of new secondary phases (Laves phase, modified Z-phase), growth of precipitates and recovery of the tempered martensite matrix. After long-term exposure this may impair the mechanical properties, including creep strength. A better understanding of the long-term microstructural evolution under creep or thermal exposure can be a key for the improvement of these heat resistant steels.

The creep strength of P91 steel combines some solid solution strengthening by Mo atoms as well as precipitation strengthening by MX precipitates and $\mathrm{M}_{23} \mathrm{C}_{6}$ carbides. In the $9-12 \% \mathrm{Cr}$ tempered martensitic steels, including P91 steel, carbide-stabilised substructure strengthening is considered as the most significant creep strengthening mechanism [1], [2].

There are rather few quantitative data [3], [4] on the size of precipitates $\left(\mathrm{M}_{23} \mathrm{C}_{6}\right.$ carbides, Laves phase, MX) for the Grade 91 steel after long-term creep exposure at $600^{\circ} \mathrm{C}$. Cipolla et al. [4] reported an increase in the diameter of $\mathrm{M}_{23} \mathrm{C}_{6}$ carbides from about 100-120 $\mathrm{nm}$ in the as received steel to about $250 \mathrm{~nm}$, as

\footnotetext{
* Corresponding author

Email address: clara.panait@ensmp.fr (Clara Gabriela Panait)

${ }^{1}$ Please cite this article as: C.G. Panait et al., Materials Science \& Engineering A 527 (2010), pp. 40624069
} 
well as a mean diameter of about $400 \mathrm{~nm}$ for the Laves phases after creep exposure at $600^{\circ} \mathrm{C}$ for almost $60,000 \mathrm{~h}$. The growth rate of Laves phases is very high in the first $10^{4} \mathrm{~h}$ [4], [5]. The evolution of the matrix substructure (sub-grains, dislocation density) during creep of this steel was scarcely investigated [6], [7], [8]. A preferential recovery of the microstructure in the vicinity of prior austenite grain boundaries was reported after $34,141 \mathrm{~h}$ at $600^{\circ} \mathrm{C}[6],[9],[10]$. To the authors' knowledge there are no quantitative data on the size of subgrains, dislocation density and MX-type precipitates in the Grade 91 steel after more than $10^{5} \mathrm{~h}$ of creep or thermal aging exposure at $600^{\circ} \mathrm{C}$.

P91 steel belongs to the family of 9-12\% Cr tempered martensitic steels and similar evolution of subgrains, dislocation density are expected to happen during long-term creep exposure. The purpose of this paper is to report quantitative data on the microstructural evolution of this steel during long-term creep exposure and thus to enrich the scarcely published data on this issue.

Microstructural evolution of a 12\% Cr tempered martensite steel (German Grade X20) during long-term aging and creep was investigated using interrupted creep tests loaded for $12,456 \mathrm{~h}, 51,072 \mathrm{~h}, 81,984 \mathrm{~h}$ and $139,971 \mathrm{~h}$ (ruptured) at $550^{\circ} \mathrm{C}$ under $120 \mathrm{MPa}$ [11], [12], [13]. Coarsening of subgrains, loss of the correlation between carbides and subgrain boundaries and an increase in the fraction of low-angle boundaries were reported recently [11], [12], [13]. The interaction between the free dislocations with particles and subgrain boundaries was described for instance in refs. [14], [15].

The present study is a part of a comprehensive characterization of a P91 steel specimen crept at $600^{\circ} \mathrm{C}$, $80 \mathrm{MPa}$ for $113,431 \mathrm{~h}$ including evaluation of precipitation, subgrain and dislocation density. $\mathrm{M}_{23} \mathrm{C}_{6}$ carbides, Laves phases and Z-phase precipitation as well as creep damage in that specimen were already investigated using transmission electron microscopy on extractive replicas and scanning electron microscopy [16]. The equivalent diameter of $\mathrm{M}_{23} \mathrm{C}_{6}$ carbides increases from about $150 \mathrm{~nm}$ in the as-received state up to $300 \mathrm{~nm}$ after creep. The size distribution of Laves phases after creep exposure was measured and a mean diameter of $400 \mathrm{~nm}$ was observed. Only a few particles of the modified Z-phase after $113,431 \mathrm{~h}$ of creep at $600^{\circ} \mathrm{C}$ were reported [16]. Creep damage was observed throughout the gauge area of the specimen, quantitative data on the size and number of cavities along specimen axis are given in ref. [16]. Compared to the as-received steel (230 HV0.5), the crept specimen showed a lower hardness of 200 HV0.5 in the gauge area and 220 HV0.5 in the head of the specimen. The decrease in hardness during both long term exposure to creep and to thermal aging is an indication of microstructural evolution and creep damage development.

To complete the characterization of microstructural evolution and deformation mechanisms in that specimen, the present study is devoted to both MX precipitates and recovery (change in dislocation density and/or in sub-grain size) of the tempered martensite matrix, as well as their impact on the creep deformation resistance.

\section{Experimental procedure}

\subsection{Materials and creep behavior}

The P91 steel was delivered by Salzgitter Mannesmann Forschung $\mathrm{GmbH}$ as a pipe, $121 \mathrm{~mm}$ in outer diameter and $20 \mathrm{~mm}$ in wall thickness. The chemical composition (wt.\%) is as follows: $0.1 \mathrm{C} ; 0.36 \mathrm{Si}$; $0.41 \mathrm{Mn} ; 0.015 \mathrm{P} ; 0.003 \mathrm{~S} ; 0.059 \mathrm{~N} ; 0.022 \mathrm{Al} ; 8.43 \mathrm{Cr} ; 0.92 \mathrm{Mo} ; 0.04 \mathrm{Cu} ; 0.068 \mathrm{Nb} ; 0.11 \mathrm{Ni} ; 0.20 \mathrm{~V}$. The pipe was subjected to the following heat treatment: austenitisation at $1050^{\circ} \mathrm{C} / 1 \mathrm{~h} /$ air cooling followed by tempering at $730^{\circ} \mathrm{C} / 1 \mathrm{~h}$ and $750^{\circ} \mathrm{C} / 1 \mathrm{~h} /$ air cooling.

The creep test was carried out at $600^{\circ} \mathrm{C}$ under constant load corresponding to an initial tensile stress of $80 \mathrm{MPa}$. The investigated crept specimen exhibited an elongation of $7.3 \%$, reduction of area of $37 \%$ and a rupture time of $113,431 \mathrm{~h}$.

Creep data in figure 1 show that the minimum strain rate e.g. $1.1 \times 10^{-5 \%} / \mathrm{h}$ (i.e. $3.06 \times 10^{-11} \mathrm{~s}^{-1}$ ) is achieved after almost 30,000h (figure 1b) and corresponds to a strain of $\sim 0.8 \%$ (figure 1c). Thus, this specimen shows similar minimum creep rate at similar strain and creep time compared to that investigated in ref. [12] (i.e. X20 steel, $550^{\circ} \mathrm{C}, 120 \mathrm{MPa}$, fracture time almost $140,000 \mathrm{~h}$, minimum creep rate of $3 \times 10^{-11} \mathrm{~s}^{-1}$ at a strain of $\sim 1 \%$, creep time $\sim 30,000 \mathrm{~h}$ ). Less than $4 \%$ of strain was measured after $10^{5} \mathrm{~h}$. Due to the difference in test temperature and chemical composition the underlying microstructural evolution of the two steels is different (e.g. size distribution of Laves phases at least [12], [16]). 


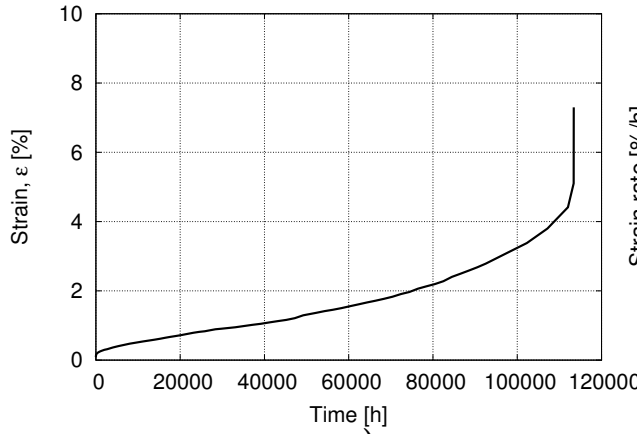

a)

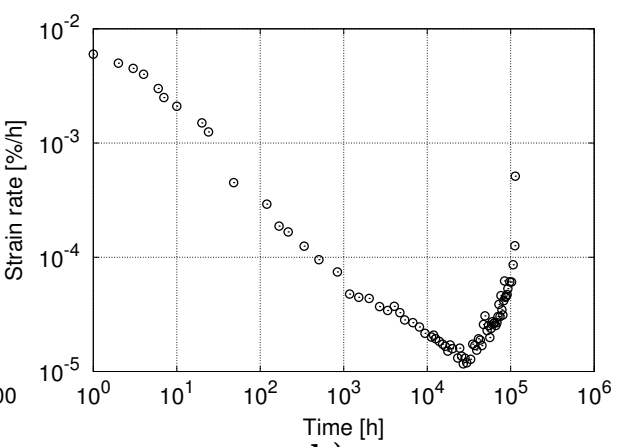

b)

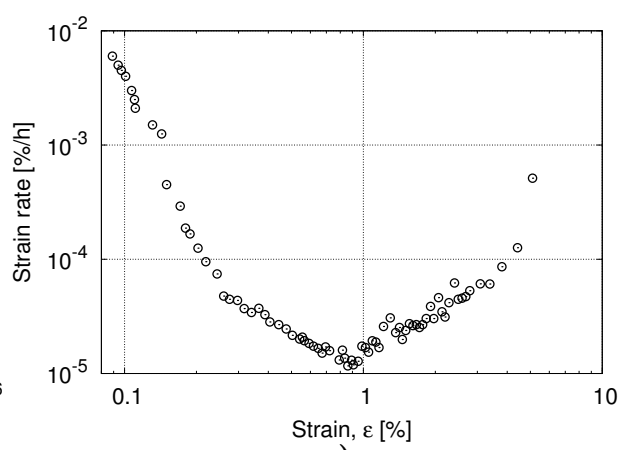

c)

Figure 1: Long term creep data for the investigated P91 steel specimen $\left(80 \mathrm{MPa}, 600^{\circ} \mathrm{C}\right)$. a) Creep strain as a function of time; b) Strain rate as a function of time; c) Strain rate as a function of strain

Figure 2 shows the microstructure of the as received P91 steel, which consists of tempered martensite with carbides and carbonitrides precipitates. Boundaries between prior austenite grains, packets, blocks, laths are mainly decorated with $\mathrm{M}_{23} \mathrm{C}_{6}$ carbides $(\mathrm{M}=\mathrm{Cr}$, $\mathrm{Fe}, \mathrm{Mo})$; some of them are underlined with arrows in Figure 2a. The MX carbonitrides $(\mathrm{M}=\mathrm{V}, \mathrm{Nb}$ and $\mathrm{X}=\mathrm{C}, \mathrm{N})$ precipitated finely and with a high number density within the laths. A high dislocation density is observed inside subgrains (figure $2 \mathrm{~b}$ ).

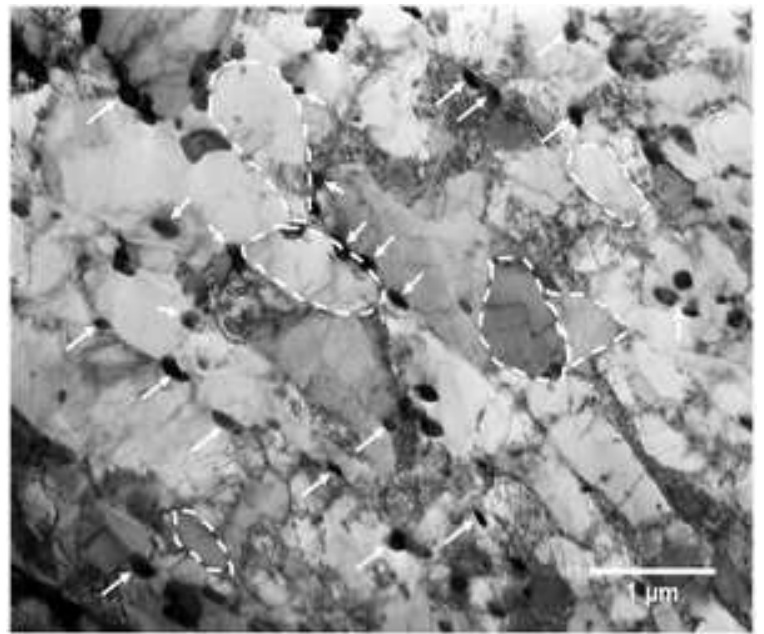

a)

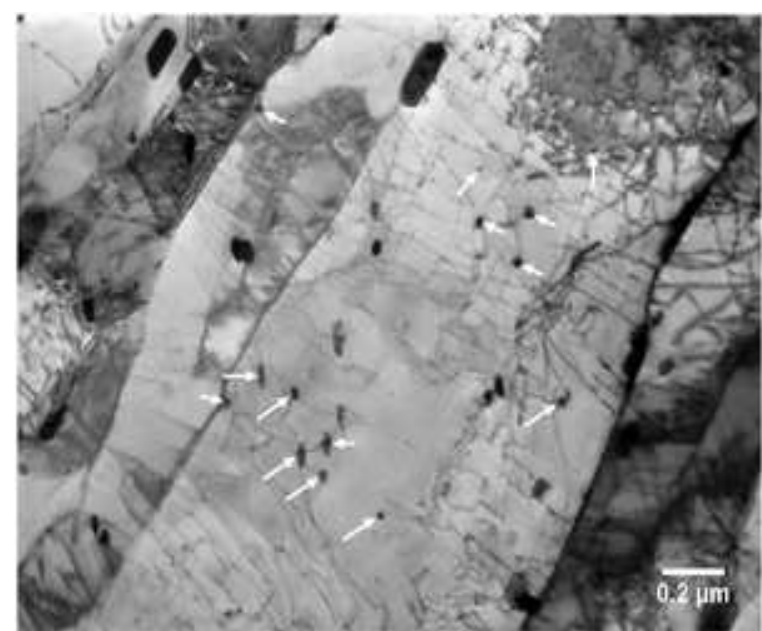

b)

Figure 2: Bright-field transmission electron micrographs of the as received P91 steel. Arrows indicate $\mathrm{M}_{23} \mathrm{C}_{6}$ carbides (a) and MX precipitates (b). Some subgrains are underlined with dotted lines in (a).

\subsection{Transmission electron microscopy (TEM) investigations}

The TEM investigations were performed using a JEOL JEM 200CX equipped with an energy dispersive $\mathrm{X}$-ray spectrometer (EDS). Thin foils for microstructural investigations after creep test were taken from the head (examined as a thermal exposed steel) and from the gauge length (examined as a creep deformed steel) of the specimen at a distance of $20 \mathrm{~mm}$ from the fracture surface, well within the homogeneously deformed part of the specimen. They were electrolytically thinned in a solution of $95 \%$ acetic acid and $5 \%$ perchloric acid. 
Quantitative microstructural characterization was realized using the ImageJ 1.38X commercial software. The MX precipitates and subgrains were manually indicated on TEM bright field images. For illustration some subgrains are indicated with dotted lines in Figure 2a. Two values of parameters of the MX precipitates (resp. subgrains) were determined namely the equivalent circle diameter $(E C D)$ and the mean diameter $(D)$ of precipitates (resp. subgrains) by using the following formulas:

$$
E C D=2 \sqrt{\frac{A}{\pi}} ; \quad D=\frac{P}{\pi}
$$

where: $A$ is the precipitate (or subgrain) area and $P$ is the precipitate (or subgrain) perimeter. A shape coefficient $(f)$ was also calculated for the MX-type precipitates and subgrains:

$$
f=4 \pi \frac{A}{P^{2}}
$$

A value of 1 for the shape coefficient indicates a circular shape. For each kind of measurements, about ten TEM images were used at several magnifications going from $\times 7,000$ and $\times 10,000$ (for subgrain microstructural characterization) to $\times 37,000$ and $\times 50,000$ (for quantification of MX-type precipitates and dislocations). The MX-type precipitates were identified using both selected area electron diffraction and EDS. For the acquisition of TEM images used for subgrain characterization, the bright-field image contrast was optimized to reveal subgrain boundaries instead of revealing dislocations or MX-type precipitates.

The average dislocation density $(\rho)$ within the subgrains (i.e. so-called free dislocations), was determined using a mean linear intercept method (recommended and first used by [17]) on TEM images with optimized contrast using the following equation:

$$
\rho=\frac{2 X \sum_{i} n_{i}}{e \sum_{i} l_{i}}
$$

with $e$ the measured thickness of the thin foil, $n_{i}$ the number of intersections between segment number $i$ and a dislocation, $X$ a factor introducing the proportion of invisible dislocations of $\frac{a}{2}\langle 111\rangle$ Burgers vectors in various reflection conditions (its value was estimated to be 2 for all the TEM images) and $l_{i}$ the length of segment $i$.

The mean linear intercept method consists in overlapping a grid of horizontal and vertical lines on subgrains and counting the intersections of dislocations with grid lines. The number of vertical and horizontal grid lines is adjusted in relation with the size and shape of subgrains in a such way to keep a constant grid spacing. This method is generally used to evaluate dislocations density, see for instance ref. [8], [15], [18], [19].

\subsection{Electron Backscatter Diffraction (EBSD) investigations}

Electron backscatter diffraction (EBSD) maps were acquired from the longitudinal cross-section of the creep specimen at $20 \mathrm{~mm}$ from the fracture surface and from the steel in the as-received condition with a ZEISS DSM 982 Gemini Shottky field emission gun (FEG) SEM equipped with a Hjelen-type camera and TSL OIM facilities. Acquisition and indexation of diffraction patterns were realized using dedicated softwares such as NORDIF 1.3.0 and TSL OIM Data Collection 5.2 respectively. EBSD measurements were conducted with step size of $40 \mathrm{~nm}$ and $150 \mathrm{~nm}$ at $20 \mathrm{kV}$, working distance $19 \mathrm{~mm}$, tilt angle $70^{\circ}$, aperture $120 \mu \mathrm{m}$, probe current between 0.1 and $1 \mathrm{nA}$.

The EBSD maps were acquired together with a backscattered electron (BSE) image (taken at $0^{\circ}$ specimen tilt), where the contrast is highly sensitive to the crystallographic orientation of the sample normal (i.e. of the primary electron beam). Laves phases, enriched in Mo, are also clearly visible in the BSE mode as bright precipitates in a dark matrix thanks to their high average atomic number.

The first map to be obtained is the image quality map, which reports, for each analysis, the ability of the software to detect the diffraction bands. The brighter the gray level in that map, the better the 
diffraction conditions. Image quality is sensitive to the crystal orientation, as well as to the channelling effect that yields the BSE image contrast. In addition, image quality is very sensitive to crystal defects such as dislocations. As soon as dislocations are clustered somewhere, the EBSD pattern quality decreases. Thus, the image quality map is very sensitive to the presence of boundaries, even for very low angle boundaries $(L A B s)$. Tak et al. [13] investigated the microtexture evolution of a X20 steel after long-term exposure considering a minimum misorientation angle of $1^{\circ}$. In our investigated samples the density of $L A B s$ with a misorientation of $\sim 1^{\circ}$ was so high that we were not able to distinguish true LABs from measurements artefacts. Thus, a minimum misorientation angle of $2^{\circ}$ was considered to process the EBSD data.

The inverse pole figure (IPF) map is colour-coded according to the orientation of a given direction of the sample in the crystal frame. The color key is recalled next to each IPF map. Note that the color is not sensitive to any rotation about that given direction of the sample, so that two IPF maps are generally needed to discriminate between grains.

In addition to IPF, one may calculate the misorientation between neighboring pixels and assign a color code to any pair of pixels whose misorientation meets a given criterion. This helps investigations whether a boundary imaged in the image quality maps corresponds to a high or to a low misorientation, or even to negligible misorientation between neighboring crystals. This is particularly useful to investigate subgrain boundaries. In all maps, the color code for boundaries is recalled according to the misorientation angles.

\section{Experimental results}

\subsection{Transmission electron microscopy investigations}

\subsubsection{Dislocation density}

The dislocation density measured after thermal exposure and after creep deformation is shown in table 1. The values are higher than those found for tempered P91 steel in ref. [8]. Nevertheless, in the crept material, the dislocation density is about twice lower than that of the as received material (Table 1). Still a rather high dislocation density can be observed after such a thermal exposure, figure 3 .

The dislocation density measured in the crept material is almost ten times higher than that predicted by the well-known relation of material science $\left(\rho<(\sigma b G)^{2} \approx 2.5 \times 10^{13} \mathrm{~m}^{-2}\right)$ but corresponds to values of dislocation density reported for the $9-12 \% \mathrm{Cr}$ tempered martensitic steel after creep exposure at $600^{c}$ irc C$625^{c}$ irc C, [20], [21].

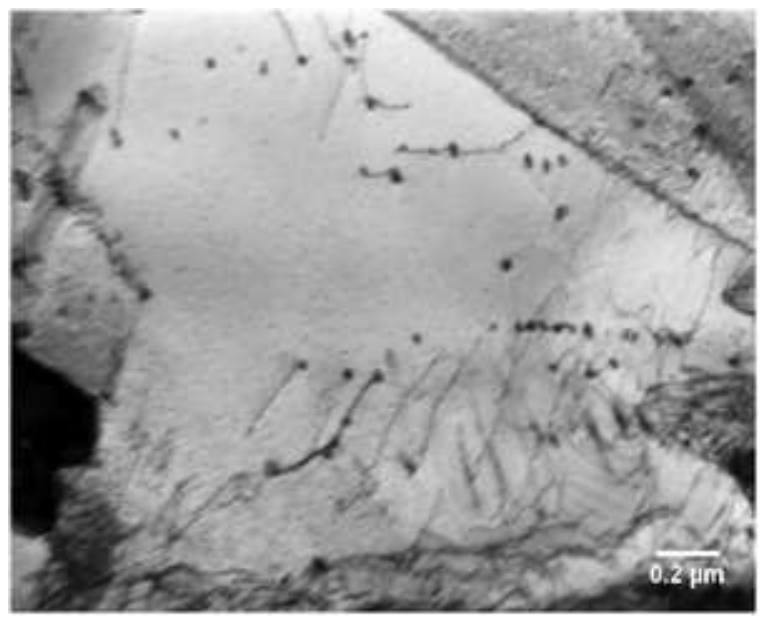

a)

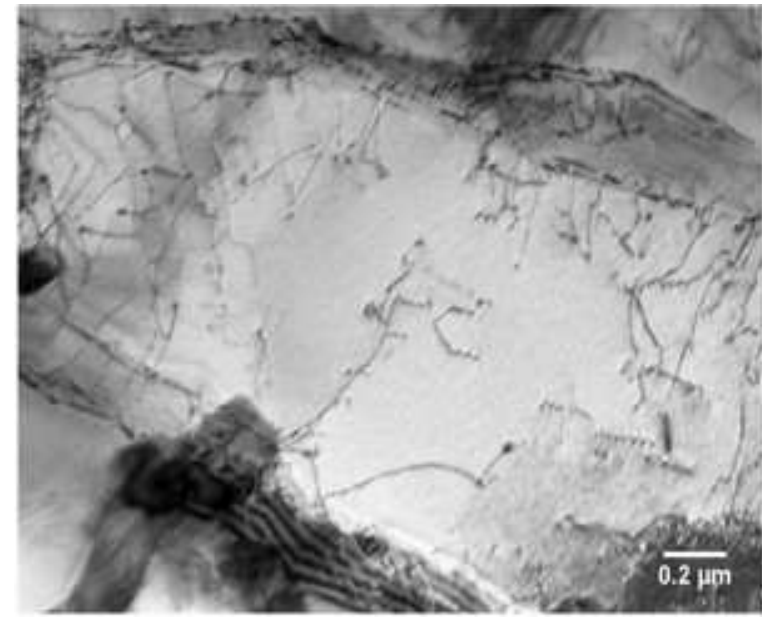

b)

Figure 3: Microstructure of (a) the gauge length (creep tested) and (b) the head (thermal exposure) showing dislocations pinned by MX-type precipitates 
Table 1: Dislocation density measured on TEM thin foils

\begin{tabular}{|c|c|c|c|}
\hline & \multirow{2}{*}{ As-received } & \multicolumn{2}{|c|}{ After 113431h of creep at $600^{\circ} \mathrm{C}$} \\
& & Head & Gauge length \\
\hline Dislocation density & $4.5 \pm 1.9 \times 10^{14} \mathrm{~m}^{-2}$ & $2.2 \pm 1.3 \times 10^{14} \mathrm{~m}^{-2}$ & $1.8 \pm 1.7 \times 10^{14} \mathrm{~m}^{-2}$ \\
\hline
\end{tabular}

The dislocation density of the specimen after thermal exposure is almost the same as in the creep deformed sample. This suggests that creep deformation in the case of dislocation creep and static recovery during thermal exposure influenced in the same manner the dislocation density whithin subgrains. This results strongly differs from that of ref. [12], were a two-fold decrease in dislocation density was found after thermal exposure and a more than ten-fold after creep. Note, however, that the initial dislocation density $\left(\cong 10^{14} \mathrm{~m}^{-2}\right)$ was lower and the test temperature also lower than in the present study.

Dislocations whithin subgrains (i.e. mobile dislocations) are carriers of plastic deformation under creep conditions and the creep rate $(\dot{\varepsilon})$ is a function of the mean dislocation velocity $(v)$ and the density of mobile dislocations $(\rho)$ as follows [22]:

$$
\dot{\varepsilon}=\frac{\rho b v}{M}
$$

where $b$ is the Burgers vector and $M$ is a Taylor factor. Considering the minimum creep rate of the specimen e.g. $1.1 \times 10^{-7} \mathrm{~h}^{-1}$, the measured dislocation density in the gauge part and $b=0.254 \mathrm{~nm}, M=3$ from ref. [22], a mean dislocation velocity of $2 \times 10^{-15} \mathrm{~m} / \mathrm{s}$ is obtained. This value is much lower than the dislocation velocity of $2.3 \times 10^{-3} \mathrm{~m} / \mathrm{s}$ evaluated by in-situ TEM observations in a Fe-Mo alloy $(<0.001 \mathrm{C}-1.2 \mathrm{Mo}-0.02 \mathrm{~N}$ $0.4 \mathrm{Si}$, wt. \%) at $738^{\circ} \mathrm{C}$, under a stress actiong on dislocations of $5.3 \mathrm{MPa}$ [23]. This is probably mainly due to different testing temperatures and different levels of stress.

The density of mobile dislocations was also used to assess the solid solution strengthening effect of Mo atoms, by using the formula given in [22]

$$
\sigma^{*}=\frac{M \dot{\varepsilon}}{\rho b B}
$$

where $\sigma^{*}$ is the backstress due to solid solution strengthening; $\dot{\varepsilon}$ is the minimum creep rate and $B$ is the dislocation mobility. There are several possibilities for assigning a value to $B$ based on the work of Terada et al. [23] on Fe-Mo alloys. By using their figure 10 for $\mathrm{T}=600^{\circ} \mathrm{C}$ and a Mo content of 0.53 at. $\%$ one gets $\mathrm{B}=10^{-16} \mathrm{mPa}^{-1} \mathrm{~s}^{-1}$ (with the curves corresponding to 0.5 at.\%Mo and their numerical simulation) and $\mathrm{B}=4 \times 10^{-17} \mathrm{mPa}^{-1} \mathrm{~s}^{-1}$ (if following the curve corresponding to 2.0 at.\%Mo and the experimental value found for 0.7 at.\%Mo). These values can reasonably be taken as two extreme possible values for $B$ after Terada et al. [23]. This is much higher than the value taken by Hald [22] in his calculations for a P92 steel.

By taking $M=3, \rho=1.8 \times 10^{14} \mathrm{~m}^{-2}, b=2.54 \times 10^{-10} \mathrm{~m}$ and $\dot{\varepsilon}=3.06 \times 10^{-11} \mathrm{~s}^{-1}$ and the extreme values of $\mathrm{B}$ one finds that $\sigma^{*}$ should range between $2 \times 10^{-5} \mathrm{MPa}$ and $5 \times 10^{-5} \mathrm{MPa}$. Note that taking for $B$ the same value as Hald did yields a value of $8 \times 10^{-3} \mathrm{MPa}$. Thus if following Hald's approach [22], whatever the value taken for the density of mobile dislocations (experimental values or above mentioned theoretical value of $2.5 \times 10^{13} \mathrm{~m}^{-2}$ ) within the range used here, solid solution strengthening by Mo is found to be negligible and Mo depletion due to precipitation of Laves phases should not be considered as the major microstructural evolution affecting creep strength.

However, one must keep in mind that short-term thermal aging (about $10^{4} \mathrm{~h}$ ) is known to decrease the creep strength of this family of steels [24], while mainly affected by precipitation of dissolved $\mathrm{W}$ into Laves phases [25]. Thus the role of $\mathrm{W}$ in the creep resistance is not fully understood. Nevertheless, one has also to consider two other possibilities for material softening i.e. loss of pining effect by MX precipitates and subgrains size evolution. 


\subsection{2. $M X$-type precipitates}

The MX carbonitrides $(\mathrm{M}=\mathrm{Nb}, \mathrm{V}, \mathrm{Cr} ; \mathrm{X}=\mathrm{C}, \mathrm{N})$ are homogeneously distributed within the martensite laths. The MX carbonitride precipitation only occurs during tempering. The size of MX carbonitrides is of about $20-40 \mathrm{~nm}$. These precipitates are very stable against coarsening at temperatures below $650^{\circ} \mathrm{C}[26]$, [22], [27], [28], yet for exposure time lower than $10^{5} \mathrm{~h}$.

In the $9-12 \%$ Cr tempered martensite steels there are generally two types of MX precipitates: MX enriched in $\mathrm{Nb}$ with a spherical shape, MX enriched in $\mathrm{V}$ with a plate-like shape [18]. Low amount of the MX particles with a more complex $V$-wings shape (a Nb-rich particle with V-rich wings) are also observed. The MX precipitates enriched in $\mathrm{Nb}$ (mainly $\mathrm{NbC}$ ) are very stable at high temperature. It was reported that in P91 steel the number of these precipitates that are not dissolved after austenitisation decreases with an increase in the austenitisation temperature [29]. In this study all three types of MX-type precipitates were quantified together.

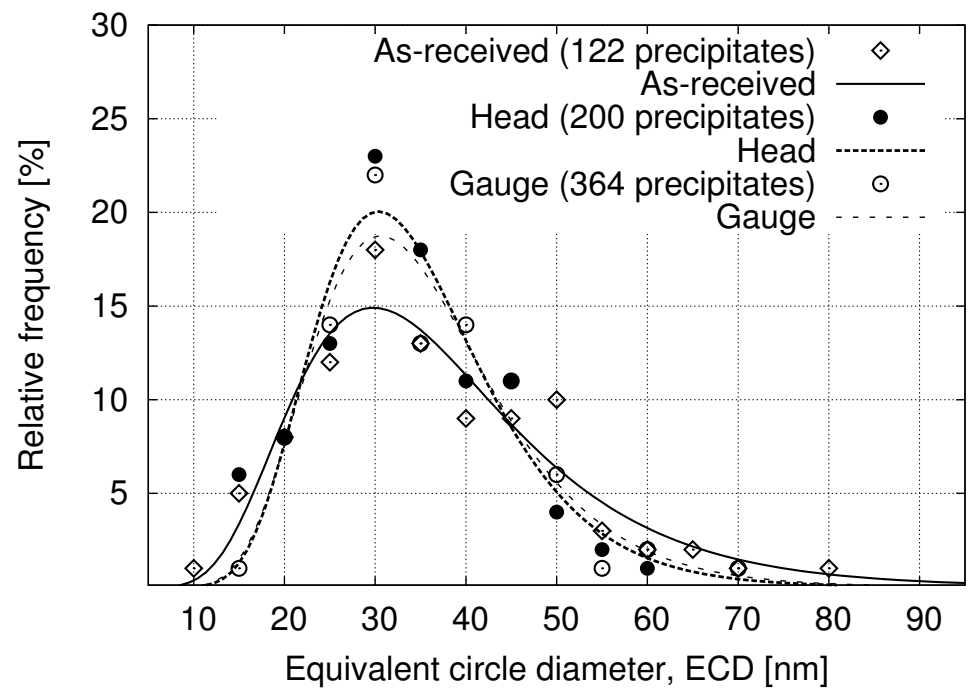

Figure 4: Size distribution of MX precipitates in all three materials from TEM image analysis Experimental results (symbols) compared with a lognormal fit (lines)

No significant effect of either thermal or creep exposure at $600 \mathrm{C}$ for $113,413 \mathrm{~h}$ was detected on the size distribution of MX-type precipitates (Figure 3). The three distributions of particles size were in good agreement with lognormal curves. The small difference between the three histograms of Figure 4 is the lack of very fine particles (the lowest ECD value) after creep or thermal exposure. It might be caused by coarsening of these particles during thermal and creep exposure or by the presence of low amount of modified Z-phase which was reported in refs. [16] and [30]. Modified Z-phase precipitation may put into solution smaller MX precipitates [20], [31], [32], this could be a reason why MX precipitates with an equivalent diameter lower than $15 \mathrm{~nm}$ were not observed after creep or thermal exposure. However, in the as received condition the number density of these MX precipitates is extremely low and after creep exposure the modified Z-phase was observed in low amounts [16] so that the apparent difference between the three histograms could also be due to sampling effects. This is also the case for the upper end of the size distribution. Thus, as already found in literature [16], it can be concluded that modified Z-phase precipitation does not have a significant influence on the distribution of MX precipitates.

No significant change in the shape coefficient of MX precipitates was detected either after long-term creep or thermal exposition. The shape coefficient is almost constant, indicating elongated precipitates. In summary, no significant evolution of MX precipitates was evidenced after long-term creep at $600^{\circ} \mathrm{C}$ for this P91 steel specimen. 


\subsubsection{Subgrain size}

After creep, most subgrains have a polygonal shape as shown in Figure 5. Significant growth of subgrains is observed in the gauge part of the specimen (Figures $5 \mathrm{~b}$ and 6 ). In the head of the specimen, some growth was also observed, but not as pronounced as in the gauge part (Figure 6). The size distribution of subgrains in the as-received steel, in thermally exposed and in creep deformed steel shows that the most significant growth of subgrains took place in the crept material, which indicates that deformation during the creep test has a significant influence on the growth of subgrains. This is confirmed by other studies [33], [34].

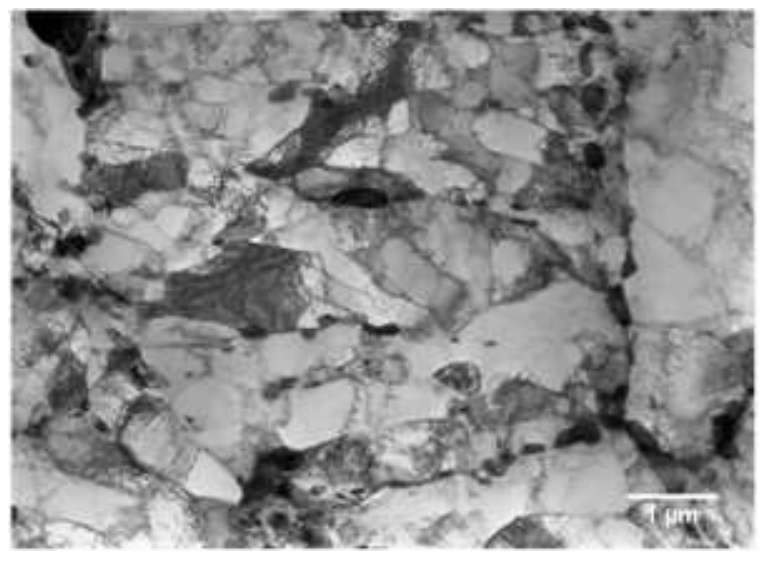

a)

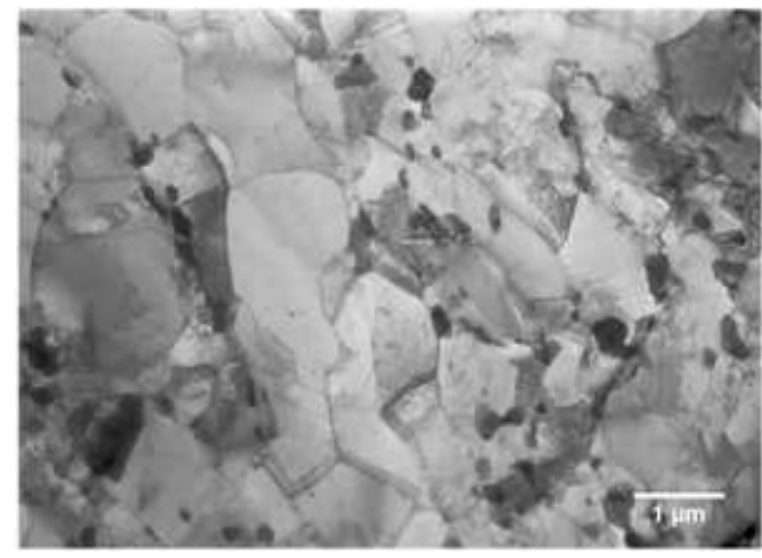

b)

Figure 5: Microstructure of the P91 steel after creep at $600^{\circ} \mathrm{C}$ showing polygonised subgrains a) head and b) gauge length

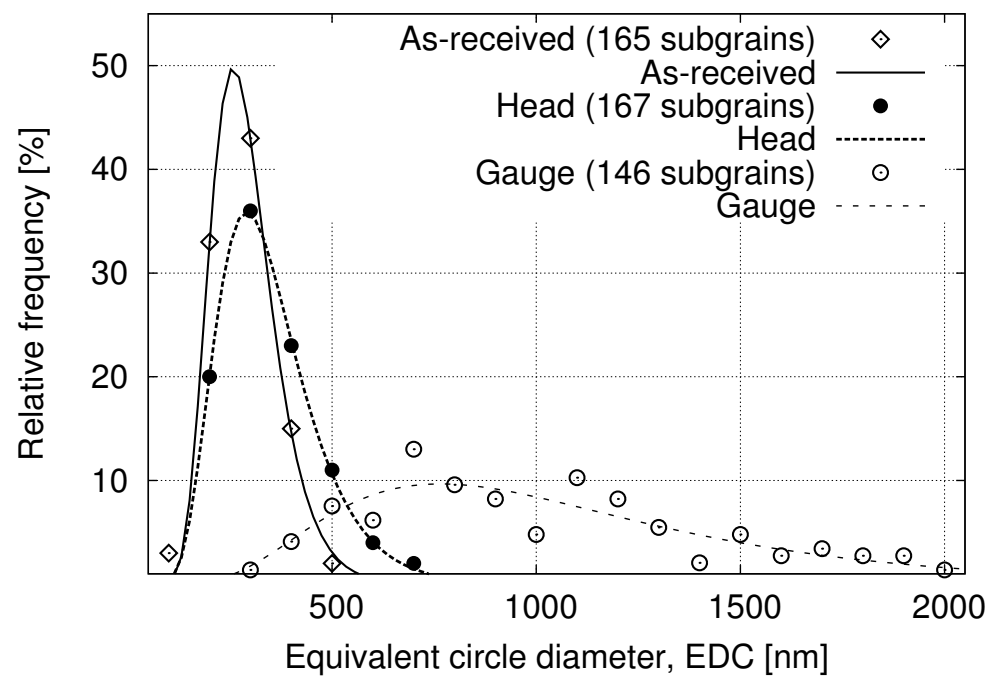

Figure 6: Size distribution of subgrains in the as received, thermally aged and crept materials (TEM image analysis). Experimental results (symbols) compared with a lognormal fit (lines)

No preferential recovery of the matrix (growth of subgrains) was observed in the vicinity of prior austenite grains boundaries as reported in ref. [6]. It is to be mentioned that using TEM techniques it is rather difficult to distinguish prior austenite grain boundaries from block or packets martensite boundaries.

Good agreement was found when comparing the experimental results (ECD) with the evolution law of 
subgrain sizes in the same manner as done by Qin et al. [35]:

$$
\log \lambda=\log \lambda_{\infty}+\log \left(\lambda_{0} / \lambda_{\infty}\right) \exp (-\varepsilon / k(\sigma))
$$

where $\lambda$ represents the subgrain size, $\lambda_{0}$ is the subgrain size before creep exposure, $\lambda_{\infty}=10[G b / \sigma]$ is the steady-state subgrain size [35], [36] where $G$ is the shear modulus, $b$ is the Burgers vector, $\sigma$ is the applied stress), $\varepsilon$ is the accumulated strain and $k(\sigma) \approx 0.12$ is a growth constant.

Equation 6 suggests that subgrain growth requires strain and this is in agreement with results presented in figure 5, 6 where subgrain size increases during long-term creep exposure while it is slightly affected by the long-term aging. Equation 6 was applied in previous studies on the size evolution of subgrains during creep of $9-12 \%$ Cr tempered martensitic steels [3], [12], [37], [38].

Note that only average values of $\lambda$ and $\varepsilon$ are used together with the macroscopically applied stress, although local values of $\varepsilon$ and $\sigma$ may strongly differ from average ones. With $\lambda_{0}=320 \mathrm{~nm}, G=65 \mathrm{GPa}$ [12], $b=0.254 \mathrm{~nm}, \sigma=80 \mathrm{MPa}$, one finds $\lambda_{\infty}=2.06 \mu \mathrm{m}$. As the amount of strain in the homogeneously deformed part is not known, it has to be bounded by (upper bound) the fracture strain $\left(\varepsilon_{f}=0.07\right)$ and (lower bound) the strain corresponding to the minimum creep rate $\varepsilon_{\min }=0.01$. A typical value could be the strain at onset of final acceleration of creep (about 0.04 from figure 1a). By taking these three values one finds $\lambda=0.729 \mu \mathrm{m}(\varepsilon=0.07), \lambda=0.543 \mu \mathrm{m}(\varepsilon=0.04)$ and $\lambda=0.371 \mu \mathrm{m}(\varepsilon=0.01)$ respectively. These values have to be compared to the experimental data of figure 6 and the mean value of subgrain size in that part of the crept specimen, namely, about $1 \mu \mathrm{m}$ for $E C D$ and $1.26 \mu \mathrm{m}$ for $D$. Thus, equation 6 leads to an underestimation of the average subgrain size after long-term creep of our specimen.

The sugrain size, $\lambda$, in equation 6 represents the mean linear subgrain intercept [35] which differs from the subgrain diameter by a geometrical factor $<1$ which can be approximated from $\pi(D / 2)^{2}=D \lambda$, thus $\lambda=0.785 D$. This last relation could explain the difference between the subgrain size, $\lambda$, corresponding to $\varepsilon=0.07$, predicted by equation 6 and the subgrain size experimentally evaluated (i.e. $\mathrm{ECD}=1 \mu \mathrm{m}$ ).

\subsection{Electron Backscatter Diffraction (EBSD) investigations}

Besides TEM image analysis, SEM-BSE investigations also revealed, in a much wider field of view, a change in the substructure of the matrix. Figure 7a compared to figure $7 \mathrm{~b}$. Figure $7 \mathrm{a}$ and the corresponding inverse pole figure (IPF), figure 8a, show a typical tempered martensite matrix with blocks and packets in the as received P91 steel. The BSE image and the corresponding IPF image in figures $7 \mathrm{~b}$ and $8 \mathrm{~b}$ reveal a microstructure with polygonal shaped subgrains after creep.

In this study orientation imaging microscopy (OIM) with a step size of $40 \mathrm{~nm}$ was conducted on the as received steel and on the longitudinal cross-section of creep specimens, at $20 \mathrm{~mm}$ from fracture surface to get information about the crystal orientation of subgrains similar to those observed in TEM micrographs. Tak et al. [13] showed that high resolution OIM with a step size of $10 \mathrm{~nm}$ can reveal features that are usually only observed using TEM. Indeed, image quality (IQ) maps show close resemblance with TEM micrographs. Contrast of IQ image is very sensitive to the defects in the crystal such as dislocations, boundaries. IQ images in figures $8 \mathrm{c}$ and $8 \mathrm{~d}$ reveal the existence of some subgrains with a very low misorientation angle. For illustration the subgrains arrowed on the IQ images of figures $8 \mathrm{c}$ and $8 \mathrm{~d}$ are not recognized as individual subgrains with a specific orientation in the IPF map, this is due to a misorientation between the subgrain and the neighbouring crystal that was lower than $2^{\circ}$. This suggests that subgrains within a given martensite lath measured on TEM images have very close crystal orientations.

Crystal orientation mapping implemented in TEM is not expected to give more accurate information about the crystal orientation of subgrains revealed in bright field micrographs. In fact such investigations with a step size of $\sim 40 \mathrm{~nm}$ conducted on a creep-fatigued specimen revealed subgrains in bright field micrograph which were not revealed in the IPF map as having a different orientation reported to the neighboring crystals [39], i.e. results similar to those presented here. 


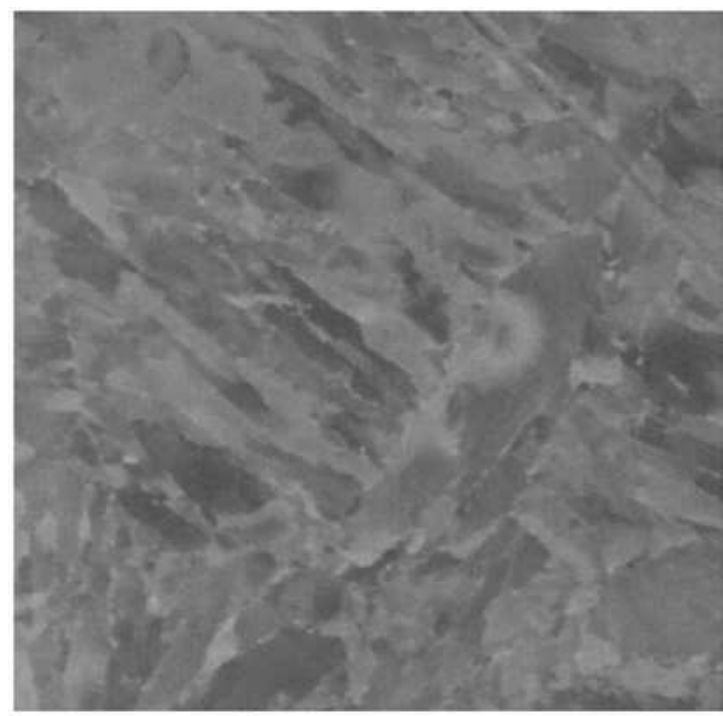

$5 \mu \mathrm{m}$

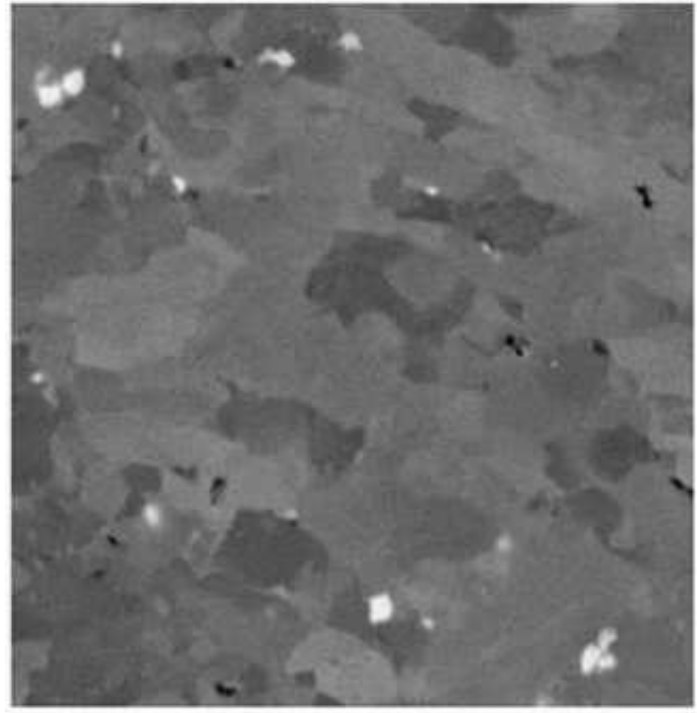

$5 \mu \mathrm{m}$

b)

Figure 7: Microstructure of the as received P91 steel (left) and after creep (right), BSE images, colloidal silica polishing

\section{Discussion}

From the above observations, one may conclude that (i) MX precipitates did not evolve during creep or thermal exposure, (ii) significant, but not extensive recovery occurred essentially due to temperature effect, and (iii) subgrain growth occurred during thermal exposure but was strongly enhanced by creep.

The solid solution strengthening effect by Mo atoms was found to be negligible using Hald's approach, so that precipitation of Laves phases should not strongly affect resistance of this steel to creep deformation. Note, however, that damage cavities were found (often next to Laves phases) throughout the gauge part of the specimen [16], so that Laves phases could affect the resistance of that steel to creep fracture.

The present results also confirmed that the evolution of subgrains size is heterogeneous. The density of mobile dislocations is hardly affected by creep; however, during thermal exposure recovery is only driven by existing dislocations (i.e. those formed in the austenite to martensite phase transformation), whereas during creep dislocations are continuously created and annihilated in a dynamic way.

As also found in other steels of the same family [12], [11] after quantitative study of both precipitation and matrix evolution during long-term creep, the present study suggests that the major contribution to the decrease in creep resistance during long-term creep exposure is subgrain growth/coarsening. Only a study involving interrupted tests as in [12], [11], [15] could provide experimental data to separately study growth and coarsening of Laves phases and of subgrains.

\section{Conclusions}

TEM results on thin foils of a $\mathrm{P} 91$ steel specimen crept for $113,431 \mathrm{~h}$ at $600^{\circ} \mathrm{C}$ compared to as received and to thermally exposed samples showed that:

- No significant change occurred in the size, shape and spatial distribution of MX-type precipitates,

- The dislocation density within subgrains was reduced by about $50 \%$ after thermal exposition, and by about $60 \%$ after creep deformation, 
- Some sub-grain growth occurred during thermal aging, much more significant and heterogeneous subgrain growth occurred after creep as shown both by TEM image analysis and EBSD mapping.

\section{References}

[1] G. Eggeler, N. Nilsvang, B. Ilschner, Steel Res. 58 (1987) 97-103.

[2] A. Kostka, K.-G. Tak, G. Eggeler, Mater. Sci. Eng. A 481-482 (2008) 723-726.

[3] J. Hald, L. Korcakova, ISIJ Int. 43 (2003) 420-427.

[4] L. Cipolla, A. DiGiafrancesco, G. Cumino, S. Caminada, in: I.A. Shibli, S.R. Holdsworth (Eds.), Proc. Creep \& fracture in high temperature components: Design \& life assessment issues, DEStech Publication ISBN 1-932078-49-5, Lancaster, U.S.A., 2005, pp. 288-299.

[5] G. Dimmler, P. Weinert, E. Kozeschnik, H. Cerjaket, Mater. Charact. 51 (2003) 341-352.

[6] F. Abe, Bainitic and martensitic creep-resistant steels, Curr. Opin. Solid State \& Mater. Sci. 8 (2004) $305-311$.

[7] J. Sanchez-Hanton, R. Thomson, Characterization of isothermally aged Grade 91 (9Cr-1Mo-Nb-V) steel by electron backscatter diffraction, Mater. Sci. Eng. A 460-461 (2007) 261-267.

[8] J. Pešička, R. Kuzel, A. Dronhofer, G. Eggeler, Acta Mater. 51 (2003) 4847-4862.

[9] H. Kushima, K. Kimura, F. Abe, Tetsu-to-Hagane 85 (1999) 841-847.

[10] H. Kushima, K. Kimura, F. Abe, in: A. Strang, R.D. Conroy, G.M. McColvin, J.C. Neal, S. Simpson (Eds.), Proc. of the 5th Inter. Charles Parsons Turbine Conference, OIM Communications Ltd., ISBN 1-86125-113-0, Cambridge, UK, 2000, pp. 590-602.

[11] A. Aghajani, F. Richter, C. Somsen, S. Fries, I. Steinbach, G. Eggeler, Scripta Mater. 61 (2009) 1068-1071.

[12] A. Aghajani, C. Somsen, G. Eggeler, Acta Mater. 57 (2009) 5093-5106.

[13] K.-G. Tak, U. Schulz, G. Eggeler, Mater. Sci. Eng. A 510-511 (2009) 121-129.

[14] A. Kostka, K.-G. Tak, R. Hellmig, Y. Estrin, G. Eggeler, Acta Mater. 55 (2007) 539-550.

[15] A. Pešička, Aghajani, C. Somsen, A. Hartmaier, G. Eggeler, Scripta Mater. 62 (2010) 353-356.

[16] C. Panait, W. Bendick, A. Fuchsmann, A.-F. Gourgues-Lorenzon, J. Besson, in: I.A. Shibli, S.R. Holdsworth (Eds.), Proc. Creep \& fracture in high temperature components: Design \& life assessment issues, DEStech Publications ISBN 978-1-60595-005-1, Lancaster, U.S.A, 2009, pp. 877-888.

[17] H. J. Klaar, P. Schwaab, W. Osterle, Prakt. Metallogr. 29 (1992) 3-25.

[18] P. J. Ennis, A. Zielińska-Lipiec, O. Wachter, A. Czyrska-Filemonowicz, Acta Mater. 45 (1997) 4901-4907.

[19] A. Zielińska-Lipiec, A. Czyrska-Filemonowicz, P. Ennis, O. Wachter, J. Mater. Proc. Technol. 64 (1997) $397-405$.

[20] A. Zielińska-Lipiec, W. Bendick, T. Koziel, B. Hahn, A. Czyrska-Filemonowicz, in: I.A. Shibli, S.R. Holdsworth (Eds.), Proc. Creep \& fracture in high temperature components: Design \& life assessment issues, DEStech Publication ISBN 978-1-60595-005-1, Lancaster, U.S.A, 2009, pp. 1067-1075.

[21] P. J. Ennis, A. Zielińska-Lipiec, A. Czyrska-Filemonowicz, Mater. Sci. Technol. 16 (2000) 1226-1232.

[22] J. Hald, Int. J. Press. Vess. Pip. 85 (2008) 30-37.

[23] D. Terada, F. Yoshida, H. Nakashima, H. Abe, Y. Kadoya, ISIJ Int. 42 (2002) 1546-1552.

[24] V. Sklenička, K. Kuchařova, M. Svoboda, L. Kloc, J. Buršik, A. Kroupa, Mater. Charact. 51 (2003) 35-48.

[25] L. J. Seung, H. G. Armaki, K. Maruyama, T. Muraki, H. Asahi, Mater. Sci. Eng. A 428 (2006) 270-275.

[26] A. Gustafson, M. Hattestrand, Mater. Sci. Eng. A 333 (2002) 279-286.

[27] K. Sawada, K. Kubo, F. Abe, Mater. Sci. Eng. A 319-321 (2001) 784-787.

[28] K. Sawada, K. Kubo, F. Abe, Mater. Sci. Technol. 19 (2003) 732-738.

[29] M. Yoshino, Y. Mishima, Y. Toda, H. Kushima, K. Sawada, K. Kimura, ISIJ Int. 45 (2005) 107-115.

[30] K. Sawada, H. Kushima, K. Kimura, M. Tabuchi, ISIJ Int. 47 (2007) 733-739.

[31] A. Golpayegani, H. Andren, H. Danielsen, J. Hald, Mater. Sci. Eng. A 489 (2008) 310-318.

[32] H. K. Danielsen, J. Hald, Mater. Sci. Eng. A 505 (2009) 169-177.

[33] B. Sonderegger, S. Mitsche, H. Cerjak, Mater. Sci. Eng. A 481-482 (2008) 466-470.

[34] A. Orlová, J. Buršík, K. Kuchařová, V. Sklenička, Mater. Sci. Eng. A 245 (1998) 39-48.

[35] Y. Qin, G. Götz, W. Blum, Mater. Sci. Eng. A 341 (2003) 211-215.

[36] W. Blum, G. Götz, Steel Res. 70 (1999) 274-278.

[37] K. Maruyama, K. Sawada, J. Koike, ISIJ Int. 41 (2001) 641-653.

[38] P. Polcik, T. Sailer, W. Blum, S. Straub, J. Burš́́k, A. Orlová, Mater. Sci. Eng. A 260 (1999) 252-259.

[39] B. Fournier, Ph.D. thesis, Ecole des Mines de Paris, Paris, France (in French) (2007). 


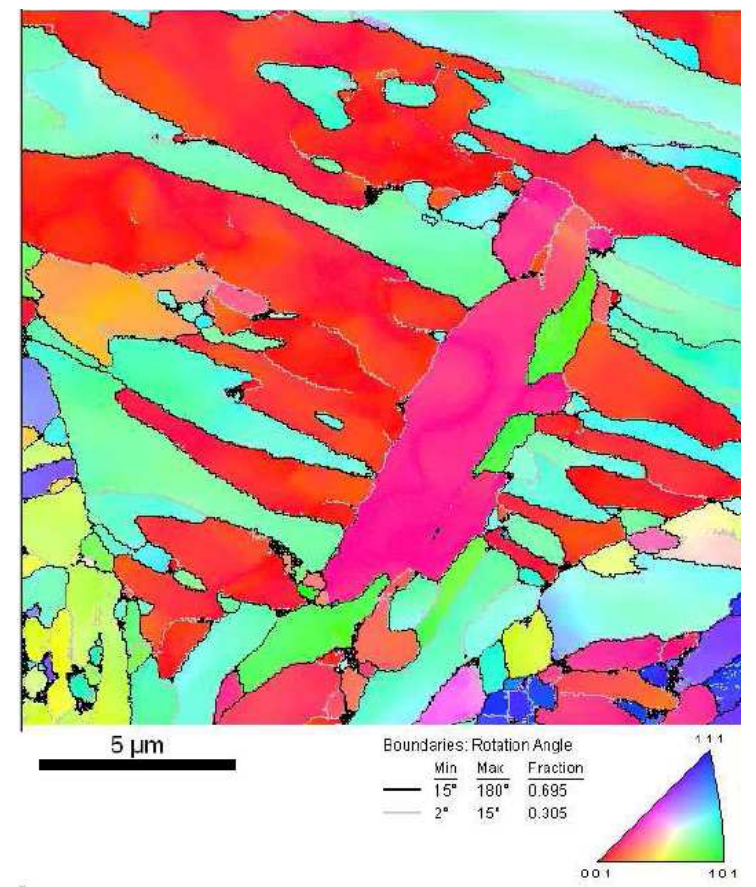

a)

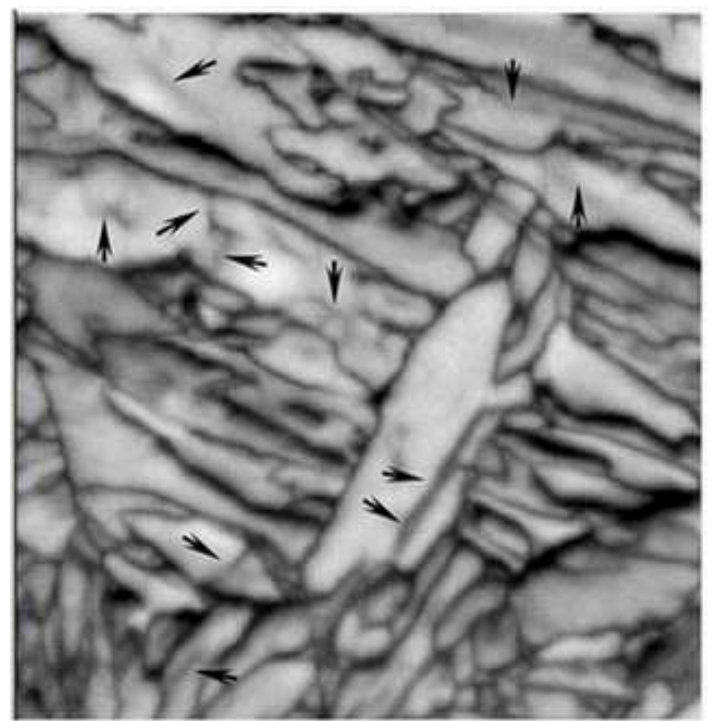

$5 \mu \mathrm{m}$

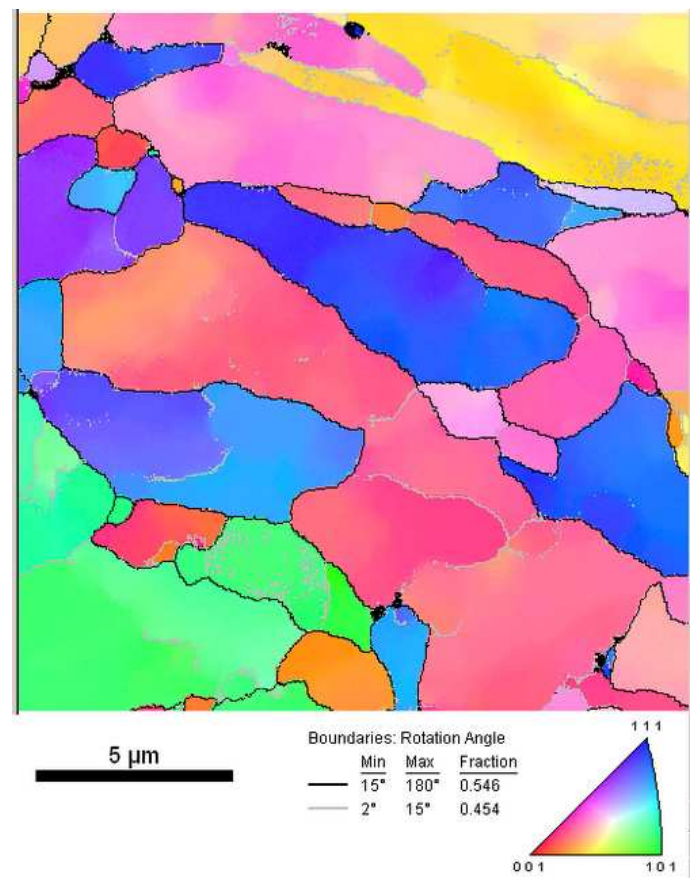

b)

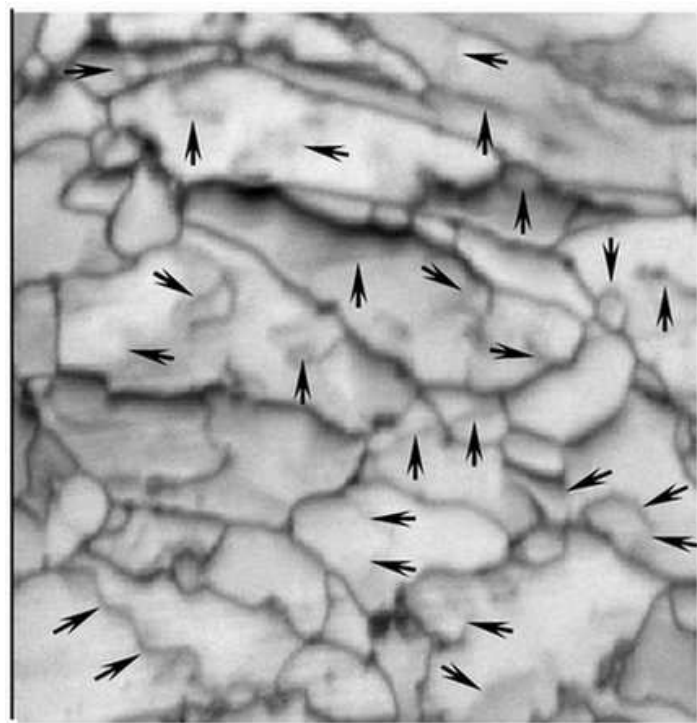

$5 \mu \mathrm{m}$

c)

d)

Figure 8: Orientation imaging microscopy (OIM) images corresponding to the images of figure $7 \mathrm{a}, \mathrm{b})$ Inverse Pole Figure (IPF) maps with orientation of sample normal in the crystal frame as key colour c, d) EBSD Image Quality map. a, c) same area as in figure $7 \mathrm{a} ; \mathrm{b}, \mathrm{d})$ same area as in figure $7 \mathrm{~b}$ 